\title{
SETDB1 plays an essential role in maintenance of gonocyte survival in pigs
}

\author{
Tiantian Liu, Pengfei Zhang, Tianjiao Li, Xiaoxu Chen, Zhenshuo Zhu, Yinghua Lyu, Xueliang Li, \\ Xiue Tian and Wenxian Zeng \\ College of Animal Science and Technology, Northwest A\&F University, Yangling, Shaanxi, China \\ Correspondence should be addressed to W Zeng; Email: zengwenxian2015@126.com
}

\begin{abstract}
Histone methyltransferase SETDB1 suppresses gene expression and modulates heterochromatin formation through H3K9me2/3. Previous studies have revealed that SETDB1 catalyzes lysine 9 of histone $\mathrm{H} 3$ tri-methylation and plays essential roles in maintaining the survival of embryonic stem cells and spermatogonial stem cells in mice. However, the function of SETDB1 in porcine male germ cells remains unclear. The aim of the present study was to reveal the expression profile and function of SETDB1 in porcine germ cells. SETDB1 expression gradually increased during testis development. SETDB1 was strongly localized in gonocytes. Knockdown of SETDB1 gene expression led to gonocyte apoptosis and a decrease in $\mathrm{H} 3 \mathrm{~K} 27 \mathrm{me}$, but no significant change in $\mathrm{H} 3 \mathrm{~K} 9 \mathrm{me}$. These observations suggested that SETDB1 is a novel epigenetic regulator of porcine male germ cells, and contributes to the maintenance of gonocyte survival in pigs, probably due to the regulation of $\mathrm{H} 3 \mathrm{~K} 27 \mathrm{me} 3$ rather than $\mathrm{H} 3 \mathrm{~K} 9 \mathrm{me}$. These findings will provide a theoretical basis for the future study of epigenetic regulation of spermatogenesis.

Reproduction (2017) 154 23-34
\end{abstract}

\section{Introduction}

Gonocytes, also known as prospermatogonia (Gaskell et al. 2004), resume cell division after birth. During their proliferation, they differentiate into spermatogonia and initiate spermatogenesis (Culty 2009). Spermatogenesis is a complicated process, by which spermatozoa is continually produced in the adult mammalian testes. At the age of 2 months, gonocytes and spermatogonia co-exist in the porcine testes (Goel et al. 2008). However, gonocytes disappear in the testes when boars reach puberty (Manku \& Culty 2015). This process of spermatogenesis requires a precisely ordered regulation of gene expression (Eddy 2002).

Gene expression is regulated by histone modifications (Spencer \& Davie 1999), which is widely related with both activation and repression of gene expression (Kouzarides 2002). Three distinct methylation states, which are mono- (me1), di- (me2), and tri- (me3) methylation that occur at lysine $(\mathrm{K})$ of histone $\mathrm{H} 3$ and $\mathrm{H} 4$ (such as K4, K9, and K27 of histone $\mathrm{H} 3$ and K20 of histone $\mathrm{H} 4$ ), are present in mammalian cells (Du \& Huang 2007). Generally, H3K4 and H3K36 are related to transcriptional activation, whereas $\mathrm{H} 3 \mathrm{~K} 9$, $\mathrm{H} 3 \mathrm{~K} 27$, and $\mathrm{H} 4 \mathrm{~K} 2 \mathrm{O}$ are associated with transcriptional repression (Martin \& Zhang 2005, Du \& Huang 2007). These histone methylations are modulated by methyltransferases and demethylases.
The methyltransferase SETDB1 (Set domain, bifurcated 1), also known as ESET, suppresses gene expression and modulates heterochromatin formation through H3K9me2/3 (Schultz et al. 2002). Previous studies demonstrated that SETDB1 plays essential roles in the maintenance of embryonic stem (ES) cells (Bilodeau et al. 2009, Yuan et al. 2009, Lohmann et al. 2010), articular cartilage and survival of neurons (Tan et al. 2012, Lawson et al. 2013). As conventional knockout of the Setdb1 resulted in mouse embryonic lethality (Dodge et al. 2004), the roles of SETDB1 for spermatogenesis have not been examined extensively. Spermatogonial stem cells, as unique adult stem cells, are the cornerstone of male fertility. Previous study indicated that SETDB1 maintained the survival of spermatogonial stem/progenitor cells via catalyzing $\mathrm{H} 3 \mathrm{~K} 9 \mathrm{me} 3$ in mice (An et al. 2014). On the other hand, it is with growing interest to use swine as non-rodent species in biomedicine and pharmaceutical research because of the similarities in anatomy and physiology between pigs and humans (Swindle et al. 2012). However, the roles of SETDB1 in porcine male germ cells remain unknown. The objective of the present study was to address the role of SETDB1 in porcine gonocytes. We found that SETDB1 was strongly expressed in the gonocytes, and that knockdown of SETDB1 led to gonocyte apoptosis and a decrease in $\mathrm{H} 3 \mathrm{~K} 27 \mathrm{me} 3$, but no change in 
H3K9me3. These data suggest that SETDB1 contributes to the maintenance of gonocyte survival in pigs.

\section{Materials and methods \\ Testis samples preparation}

Porcine testes from 7-day-old, 2-month-old and adult Landrace hybrid boars were obtained from Yangling pig farm by standard castration procedures. After castration, the testes were maintained in ice-cold PBS during transfer to the laboratory. Small pieces of testis tissue were fixed in Bouin solution overnight, washed three times in PBS and processed for histology.

\section{Preparation and enrichment of gonocytes}

The tunica albuginea was removed from the testis tissues before mincing with scissors. The minced tissue was digested with collagenase type IV $\left(2 \mathrm{mg} / \mathrm{mL}\right.$, Invitrogen) at $37^{\circ} \mathrm{C}$ for $20 \mathrm{~min}$, and washed with PBS to remove interstitial cells and red blood cells. The resulting seminiferous tubules were incubated in $0.25 \%$ trypsin-EDTA (Invitrogen) at $37^{\circ} \mathrm{C}$ for $5 \mathrm{~min}$. The reaction was stopped by fetal bovine serum (FBS; Gibco). After filtration with $40-\mu \mathrm{m}$ nylon mesh, the singlecell suspension was centrifuged at $600 \mathrm{~g}$ for $5 \mathrm{~min}$ at room temperature, and the pellets were suspended in DMEM/F12 (Invitrogen) with 2\% FBS (Gibco). Gonocytes were enriched through differential plating. In brief, the cell suspension was plated into $10-\mathrm{cm}$ dishes with $2 \times 10^{7}$ cell/dish and cultured at $37^{\circ} \mathrm{C}$ for $6 \mathrm{~h}$. The plates were pipetted gently to remove the cells that were weakly attached to the surface. The cells were transferred into new dishes, cultured over night at $37^{\circ} \mathrm{C}$ in a $\mathrm{CO}_{2}$ incubator. Next day, the supernatant cells were harvested by gently pipetting. The harvested cells were analyzed using antibody for glial cell-derived neurotrophic factor receptor alpha-1 (GFRA1), which is a surface marker for gonocytes and undifferentiated spermatogonia in pigs (Lee et al. 2013). The adherent cells were analyzed using antibody for SRY-box containing gene 9 (SOX9), which is a marker for Sertoli cells (Frojdman et al. 2000, Franca et al. 2016).

\section{RNAi lentivector, siRNA and transient transfection}

Small hairpin RNA (shRNA) targeting the porcine SETDB1 gene was designed and cloned into pCDH-U6-MCS-EF1-GreenPuro. A sequence specific to porcine SETDB1 CDNA was as follows: shRNA-1 sequence GGTGATGAGTACTTTGCCA, shRNA-2 sequence GGGATTGCCATTAAATCAA and a scramble control NC-shRNA sequence GATGAAATGGGTAAGTACA. These plasmids were co-transfected HEK 293T cells in 6-well plates with SETDB1 overexpression vector $(70-80 \%$ cell density per well). All cells were collected after $48 \mathrm{~h}$ culture and then subjected to mRNA analysis using RT-qPCR. In addition, HEK 293T cells were co-transfected with pCDH-U6-SETDB1/NCshRNA and pGag/Pol, pRev, pVSV-G plasmids to produce lentivirus.

Transfection of small interferencing RNA (siRNA) $(25 \mathrm{nM})$ corresponding to the shRNA was performed using
Lipofectamine RNAiMAX reagent (Invitrogen) according to the manufacturer's protocol.

\section{Immunohistochemistry}

The 6- $\mu \mathrm{m}$-thick sections were de-paraffinized with xylene and re-hydrated with ethanol series from $100 \%(\mathrm{v} / \mathrm{v})$ to $70 \%(\mathrm{v} / \mathrm{v})$. The slides were washed three times, each for $5 \mathrm{~min}$ in PBS, followed by $0.5 \%$ Triton X-100 in ultrapure water for $10 \mathrm{~min}$ at room temperature. The slides were washed and boiled in a solution of 0.01-M Tris-EDTA ( $\mathrm{pH}=9)$ for $15 \mathrm{~min}$ for antigen retrieval, and cooled at room temperature for $40 \mathrm{~min}$. The sections were incubated with $3 \% \mathrm{H}_{2} \mathrm{O}_{2}$ to block endogenous peroxidase, washed three times with PBS, and blocked with $10 \%$ goat serum for $2 \mathrm{~h}$ at room temperature. Subsequently, the slides were incubated with the primary antibodies against SETDB1 (1:50; Santa Cruz Biotechnology), or H3K9me3 (1:50; Millipore) at $4^{\circ} \mathrm{C}$ overnight. While some slides were incubated with blocking solution as a negative control. Next day, the slides were rinsed four times in PBS, incubated with biotinylated secondary antibody for $1 \mathrm{~h}$ at $37^{\circ} \mathrm{C}$ and then washed three times with PBS. The slides were exposed to the horse radish peroxidase at $37^{\circ} \mathrm{C}$ for $1 \mathrm{~h}$, followed by incubation in 3,3'-diaminobenzidine (CWBIO, Beijing, China) for staining and counterstained with Mayer hematoxylin solution (SigmaAldrich), and washed three times with PBS for 5 min each. Digital images were captured with the Nikon Eclipse 80i microscope camera.

\section{Immunohistofluorescence analysis}

The procedure was similar to that in immunohistochemistry section with minor modification. Briefly, the slides were incubated with $10 \%$ donkey serum for blocking nonspecific reactions at room temperature for $2 \mathrm{~h}$ and incubated with the primary antibodies against GFRA1 (1:50; Santa Cruz Biotechnology), SETDB1 (1:50; Santa Cruz Biotechnology), H3K9me3 (1:50; Millipore) and c-KIT (1:50; Santa Cruz Biotechnology) respectively, overnight at $4^{\circ} \mathrm{C}$. Next day, the sections were washed four times with PBS and then incubated with either donkey anti-Goat (1:200; Abcam) or donkey anti-Rabbit (1:100; Santa Cruz Biotechnology) antibodies for immunofluorescence labeling. Slides were washed and counterstained with DAPI (CWBIO). Fluorescent images were captured with the Nikon Eclipse 80i fluorescence microscope camera.

\section{Immunocytochemistry assay}

Gonocytes were seeded into a 96-well plate and treated with siRNA for additional $48 \mathrm{~h}$. The cells were fixed with $4 \%$ paraformaldehyde for $30 \mathrm{~min}$ at $4{ }^{\circ} \mathrm{C}$ and permeabilized for $10 \mathrm{~min}$ using $0.5 \%$ Triton-X100 solution. The cells were incubated with $10 \%$ donkey serum for blocking nonspecific reactions at room temperature for $2 \mathrm{~h}$ and then incubated with the primary antibody overnight at $4^{\circ} \mathrm{C}$. Next day, the cells were washed three times in PBS, incubated with either donkey anti-Rabbit (1:100; Santa Cruz Biotechnology) or donkey anti-Goat (1:200; Santa Cruz Biotechnology) antibodies 
for immunofluorescence labeling. Cells were washed and counterstained with DAPI (CWBIO). Fluorescent images were taken using the fluorescence microscope (Olympus).

\section{Western blot}

Testicular cells were lysed with RIPA (Beyotime Institute of Biotechnology, Jiangsu, China) that contained $20 \mathrm{mM}$ Tris- $\mathrm{HCl}$ (pH 7.5), $150 \mathrm{mM}$ sodium chloride, $1 \%$ triton $\mathrm{X}-100,0.5 \%$ sodium deoxycholate, $0.1 \%$ SDS, $2 \mathrm{mM}$ EDTA and protease inhibitors, and were centrifuged at $12,000 \mathrm{~g}$ for $10 \mathrm{~min}$ at $4{ }^{\circ} \mathrm{C}$. Cell lysates were mixed with SDS loading buffer and boiled at $100^{\circ} \mathrm{C}$ for $5 \mathrm{~min}$. Cell lysates were separated by SDS-PAGE, and transferred to PVDF membranes (Millipore). The membranes were incubated with the following primary antibodies: rabbit anti-H3K9me3 (1:1000; Millipore; 07-442), rabbit anti-H3K27me3 (1:1000; Millipore; 07-449), rabbit anti-SETDB1 (1:500; Santa Cruz Biotechnology; sc-66884), rabbit anti-EZH2 (1:1000; Cell Signaling Technology; 4905), mouse anti-beta-ACTIN (1:2000; CWBIO; CW0096M) and rabbit anti-H3 histone (1:2000; Millipore; 06-755). Secondary antibodies were horseradish peroxidase-linked anti-rabbit or anti-mouse antibody (1:5000; Abcam). The membranes were visualized on a Bio-Rad Chemidoc XRS using a Western Bright ECL Kit (Bio-Rad).

\section{Co-immunoprecipitation (Co-IP) assay}

Overexpression SETDB1 and EZH2 plasmids were co-transfected into HEK 293 T cells using Turbofect Transfection Reagent (Thermo Fisher Scientific). After $48 \mathrm{~h}$, the cells were lysed with RIPA buffer (20 mM Tris- $\mathrm{HCl}$ (pH 7.5), $150 \mathrm{mM}$ sodium chloride, $1 \%$ triton $\mathrm{X}-100,0.5 \%$ sodium deoxycholate, $0.1 \%$ SDS, $2 \mathrm{mM}$ EDTA and protease inhibitors). Cell lysates were immunoprecipitated using anti-SETDB1 (Santa Cruz Biotechnology; sc-66884) or anti-EZH2 (Cell Signaling Technology; 4905) antibody and added with protein $\mathrm{G}$ agarose beads (Millipore) overnight with constant rotation at $4{ }^{\circ} \mathrm{C}$. Finally, the protein-antibody-bead complex was washed and analyzed by Western blot.

\section{Plasmid construction and bimolecular fluorescence complementation (BiFC) assay}

SETDB1 protein contains the tudor domain, which mediates the protein-protein interactions (Yang et al. 2002). We cloned the porcine EZH2 gene and SETDB1 tudor domain to produce plasmids pBiFC-EZH2-VN173 and pBiFCSETDB12001-VC155 for BiFC assay. Briefly, DNA fragments of EZH2 and SETDB1-2001 were amplified by PCR, and cloned into the Notl/Kpnl sites of pBiFC-VN173 and EcoRI/Kpnl sites of pBiFC-VC155 respectively. PCR-amplified primers were listed in Supplementary Table 1 (see section on supplementary data given at the end of this article).

The plasmids pBiFC-EZH2-VN173 and pBiFCSETDB12001-VC155 constructs were co-transfected into HEK 293T cells using Turbofect Transfection Reagent (Thermo Fisher Scientific). After $48 \mathrm{~h}$, the fluorescence intensity was captured using a fluorescence microscope (Olympus).

\section{Quantitative RT-PCR (qRT-PCR)}

RNA was extracted from the cells or tissues with TRIzol (Invitrogen) according to the manufacturer's protocol. The reverse transcriptions were conducted using PrimeScript RT reagent Kit with gDNA Eraser (Takara). SYBR premix Ex Taq II (Takara) was used for Real-time PCR using an IQ5 (Bio-Rad). Reactions were run in triplicate in three independent experiments. The primer sequences are shown in Supplementary Table 1. The transcript abundance of each gene was normalized to the geometric mean of housekeeping gene GAPDH. Fold change in transcript abundance was analyzed according to the $2^{-\Delta \Delta \mathrm{Ct}}$ method.

\section{TUNEL staining}

To detect apoptotic cells, TdT-mediated dUTP nick end labeling assays were carried out with TUNEL BrightRed Apoptosis Detection Kit (Vazyme, Jiangsu, China) according to the manufacturer's instructions. Briefly, cells were fixed in $4 \%$ paraformaldehyde at $4^{\circ} \mathrm{C}$ for $25 \mathrm{~min}$ and washed with PBS. After being permeabilized with proteinase $\mathrm{K}(20 \mu \mathrm{g} / \mathrm{mL})$ for $5 \mathrm{~min}$ at room temperature, the cells were incubated with $50 \mu \mathrm{L} \mathrm{TdT}$ incubation buffer at $37^{\circ} \mathrm{C}$ for $60 \mathrm{~min}$ in darkness. In the end, cells were washed and observed with the fluorescence microscope (Olympus).

\section{Statistical analysis}

All the experiments were repeated at least three times. Statistical evaluation of the data was performed with one-way ANOVA with a least significant difference Tukey's test (SPSS). Data were calculated as mean \pm standard deviations (S.D.) and considered significant when the $P$ value was less than $0.05\left(^{*}\right)$, $0.01{ }^{(* *)}$ or $0.001^{(* * *)}$.

\section{Results}

\section{Expression profiles of SETDB1 in the developmental testes}

The porcine SETDB1 sequence was cloned. The resultant sequence was consistent with it in NCBI. To analysis the conservation of SETDB1 across species, the amino acids of pig (XP_005663543), mouse (NP_001157113) and human (NP_001138887) SETDB1 were aligned. The amino acid sequence of porcine SETDB1 was $95.52 \%$ homologous to human and $90.18 \%$ to mouse (Supplementary Fig. 1). These observations demonstrate that SETDB1 is highly conserved in these species studied.

The testis tissue from 7-day-old, 2-month-old and adult Landrace hybrid boars were used to reveal the expression profiles of SETDB1 during testis development. RT-PCR and Western blot assay showed that the expression of SETDB 1 was gradually increasing. It achieved the highest level at adult stage (Fig. 1A and B). However, H3K9me3 level was contrary to the SETDB1 expression. Western blot assay showed that the abundance of $\mathrm{H} 3 \mathrm{~K} 9 \mathrm{me} 3$ was 
A

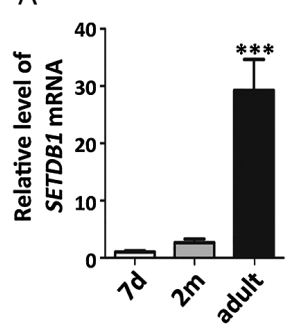

B

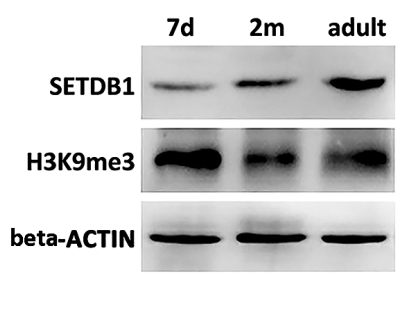

C

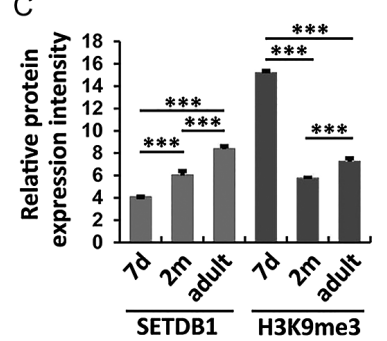

Figure 1 Expression profiles of SETDB 1 and $\mathrm{H} 3 \mathrm{~K} 9 \mathrm{me} 3$ during porcine testis development. (A) Transcripts of SETDB1 were examined by qRT-PCR in the testes from different ages (7-days, 2-months and adult) of pigs. The levels of the transcription were normalized against GAPDH.

(B) Western blot detection of SETDB1 and H3K9me3 protein levels during postnatal development of the testes. (C) Intensity analysis of SETDB1 and H3K9me3 were calculated by ImageJ. Data are presented as the mean \pm S.D., ${ }^{* * *} P<0.001$.

the highest in the neonatal piglet testis tissue, and then decreased (Fig. 1B and C).

\section{Distribution of SETDB1, H3K9me 3 and H3K27me 3 in porcine testes}

The immunohistochemistry was performed to localize the distribution of SETDB1, H3K9me3 and H3K27me3 in porcine testes. $\mathrm{H} 3 \mathrm{~K} 9 \mathrm{me} 3$ and $\mathrm{H} 3 \mathrm{~K} 27 \mathrm{me} 3$ distributed in gonocytes/undifferentiated spermatogonia, Sertoli cells and interstitial cells, whereas SETDB1 was localized in gonocytes/undifferentiated spermatogonia and interstitial cells in 1-week-old and 2-month-old testis tissues. SETDB1, H3K9me3 and H3K27me3 were localized in the spermatogonia, spermatocyte, Sertoli cells and interstitial cells in the seminiferous tubules of adult testis tissue (Fig. 2).

We further detected the distribution of SETDB1 and $\mathrm{H} 3 \mathrm{~K} 9 \mathrm{me} 3$ in undifferentiated and differentiated germ cells. SETDB1 localized strongly in cytoplasm and weakly in nuclei in GFRA1-positive spermatogonia (Fig. 3A and B). H3K9me3 showed extensive perinuclear distribution in gonocytes/undifferentiated spermatogonia (GFRA1 as a marker for gonocytes and undifferentiated spermatogonia) in the 7-day-old and 2-month-old testis tissue (Fig. 3A and B). Subsequently, SETDB1 was localized in the nuclei of undifferentiated spermatogonia (GFRA1-positive cells) and differentiated spermatogonia (C-KIT as a marker for differentiated spermatogonia) in adult testes (Fig. 4A). Interestingly, H3K9me3 showed perinuclear localization in GFRA1 positive cells, while displaying intranuclear distribution in differentiated spermatogonia (c-KIT positive cells, Fig. 4B).

\section{Expression of SETDB1 in gonocytes}

The interstitial cells and red blood cells were removed by velocity sedimentation during the digestion. The harvested seminiferous tubules from 1-week-old boar testes are mainly composed of Sertoli cells and gonocytes. Therefore, the interstitial cells were excluded from the recovered cells, and would not interfere in the accuracy for identifying gonocytes through immunocytochemistry assay of GFRA1 expression. The purity of the enriched gonocytes reached $76.5 \% \pm 3.9 \%$ (GFRA1 positive cells, Fig. 5A and B). The SETDB 1 expression in gonocytes was 8.9 times higher than that in Sertoli cells at mRNA level (Fig. 5C). SETDB1 was mainly expressed in gonocytes (Fig. 5D, E and Supplementary Fig. 2).

\section{SETDB1 knockdown induced gonocyte apoptosis}

The results of SETDB1 expressed in gonocytes revealed a unique role of SETDB 1 in gonocytes. Gonocytes were transfected with high interference efficiency siRNA-1 (Supplementary Fig. 3) designed against SETDB1-coding sequence. As shown in Fig. $6 \mathrm{~A}$ and $\mathrm{B}$, the expression of SETDB1 in SETDB1-KD gonocytes was significantly decreased at both RNA and protein level. Unexpectedly, the level of $\mathrm{H} 3 \mathrm{~K} 9 \mathrm{me} 3$ did not change in the SETDB 1-KD group. Surprisingly, SETDB1 interference resulted in a dramatic decrease of H3K27me3 level (Fig. 6C and D). In addition, immunofluorescence assay showed that the fluorescence intensity of SETDB1 significantly weakened in the SETDB1-KD gonocytes, but no change in $\mathrm{H} 3 \mathrm{~K} 9 \mathrm{me} 3$ (Fig. 6E and F). These observations indicate that SETDB1-KD lead to a decrease of H3K27me3, but little or no change on $\mathrm{H} 3 \mathrm{~K} 9 \mathrm{me} 3$ level.

Interestingly, knockdown of SETDB1 induced apoptosis (Fig. 7A). The proportion of apoptotic gonocytes was $48.7 \% \pm 5.7 \%$ in the treatment group, whereas $25.4 \% \pm 1.2 \%$ in $\mathrm{NC}$ control group (Fig. $7 \mathrm{~B}$ ). On the contrary, the depletion of SETDB 1 in Sertoli cells did not induce cell apoptosis. The number of apoptotic Sertoli cells was similar between SETDB1-KD group and the control (Supplementary Fig. 4).

Furthermore, we detected the apoptotic related proteins to confirm the apoptosis using Western blot. As shown in Fig. 7C, knockdown of SETDB1 in gonocytes led to an increase of cleaved CASP3, and a decrease of anti-apoptotic protein BCL2. The depletion of SETDB1 made neither change for the pro-apoptotic protein BAX nor the total CASP3. 
$7 d$
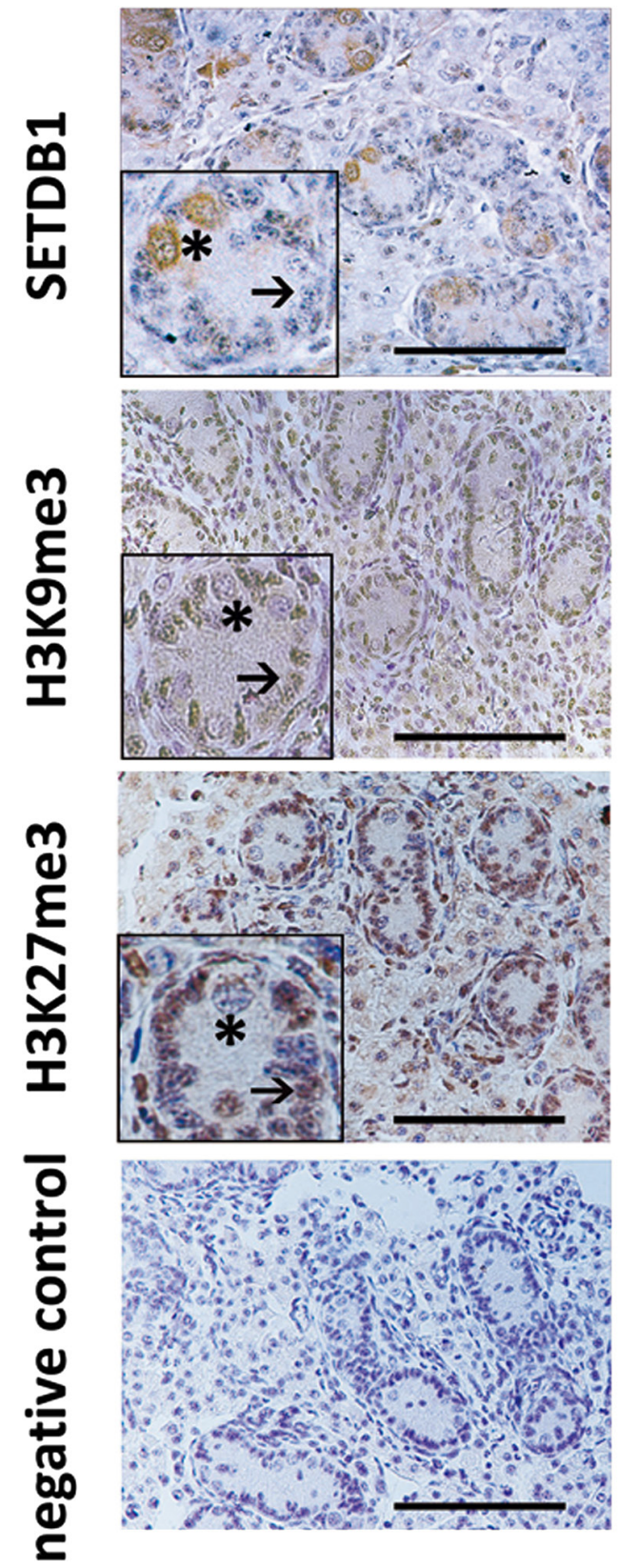

$2 m$
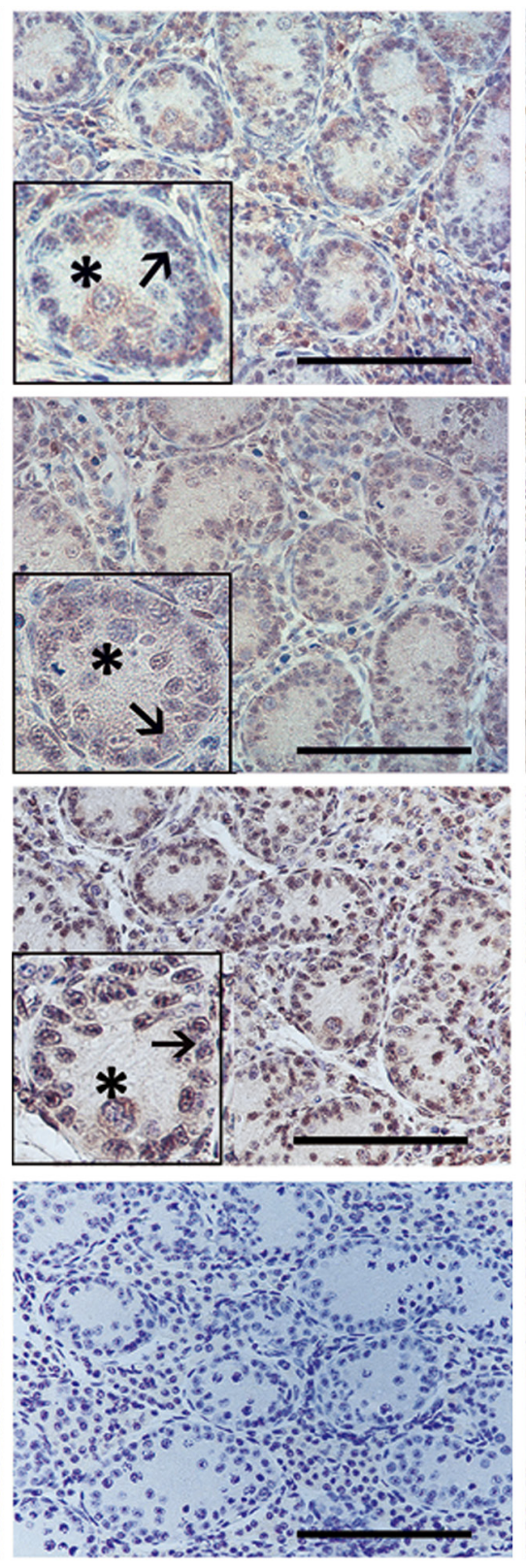

adult
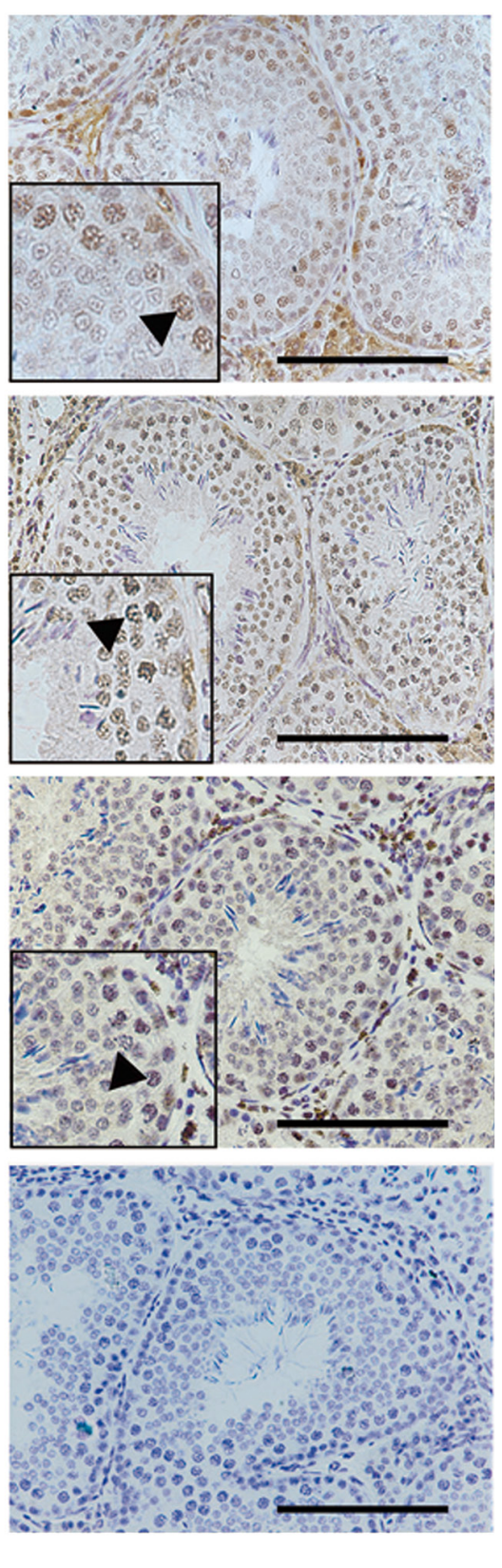

Figure 2 Immunohistochemistry detection of SETDB1, H3K9me3 and H3K27me3 levels during porcine testis development. Asterisks: gonocytes; arrows: Sertoli cells; arrowheads: pachytene spermatocytes. Bars $=50 \mu \mathrm{m}$.

In addition, to verify the interaction between SETDB1 and $\mathrm{EZH} 2$ that regulates apoptosis via depositing $\mathrm{H} 3 \mathrm{~K} 27 \mathrm{me}$, the Co-IP assay with antibodies for SETDB1 and $\mathrm{EZH} 2$ showed that CO-immunoprecipitated SETDB1 or $\mathrm{EZH} 2$ could be detected by either $\mathrm{EZH} 2$ antibody or SETDB1 antibody (Fig. 7D). In addition, BiFC assay revealed that the interaction of SETDB1 and EZH2 produced an observable fluorescence compared to the EZH2-Mock control (Fig. 7E).

\section{Discussion}

The methyltransferase SETDB1 plays an importance role in the maintenance of ES cells through repressing the expression of genes encoding developmental regulators and restricting extraembryonic trophoblast lineage potential (Bilodeau et al. 2009, Yeap et al. 2009, Yuan et al. 2009). Our previous study showed that SETDB1 was required for the survival of spermatogonial 
A GFRA1 SETDB1 DAPI
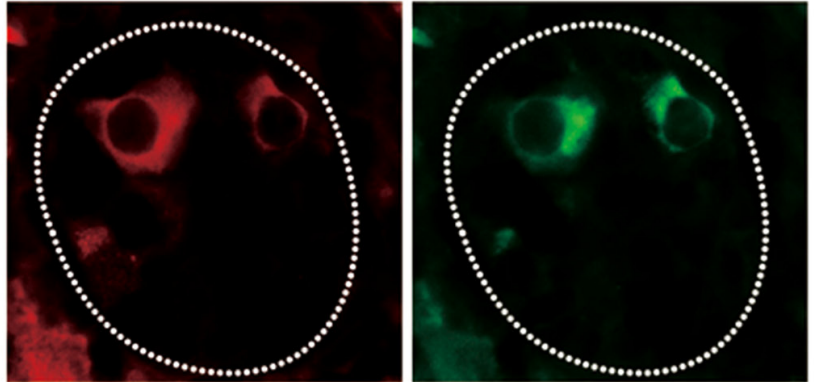

GFRA1

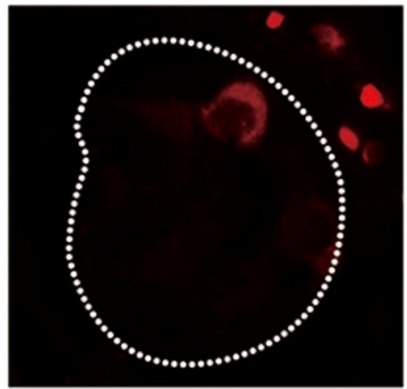

H3K9me3
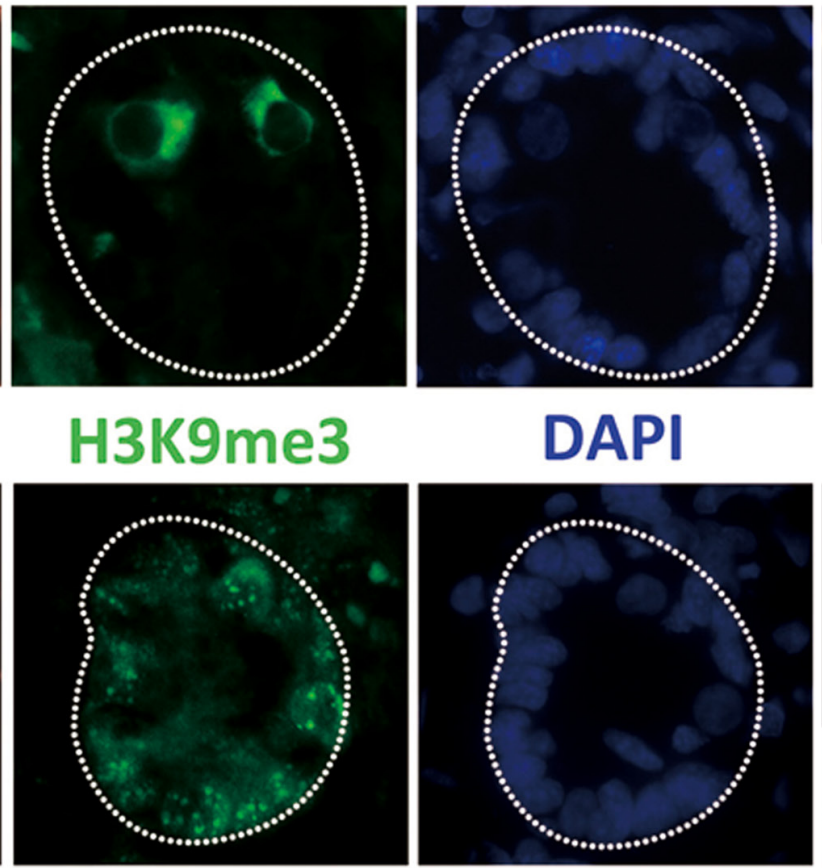

DAPI

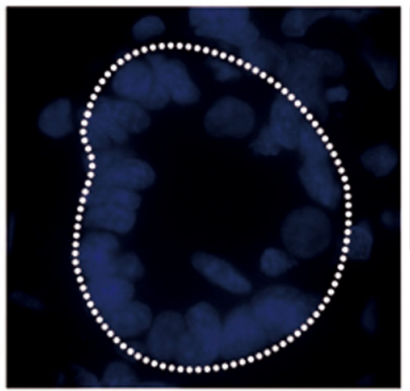

B

GFRA1

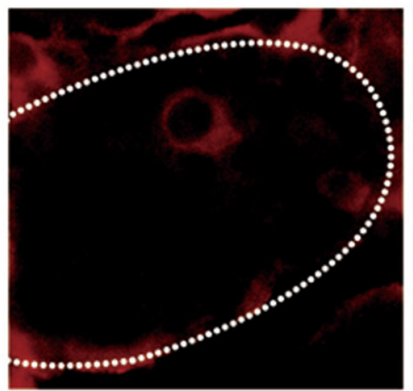

GFRA1

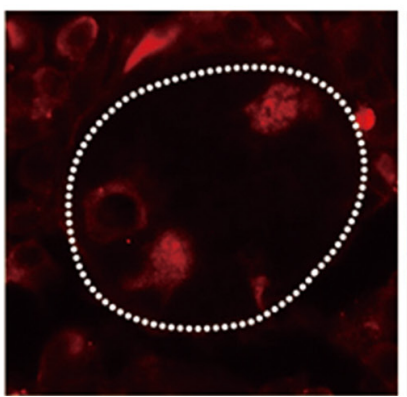

SETDB1

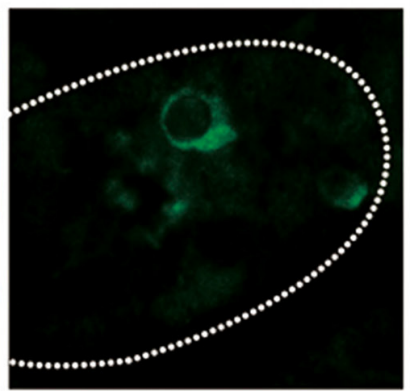

H3K9me3

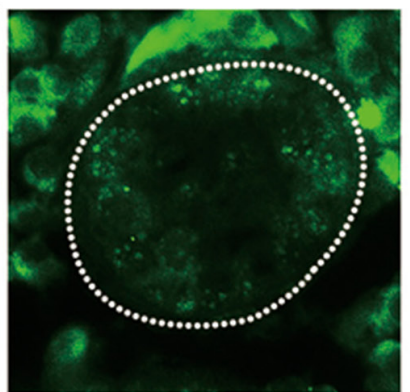

DAPI

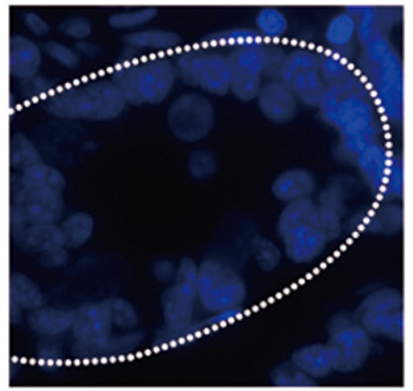

DAPI

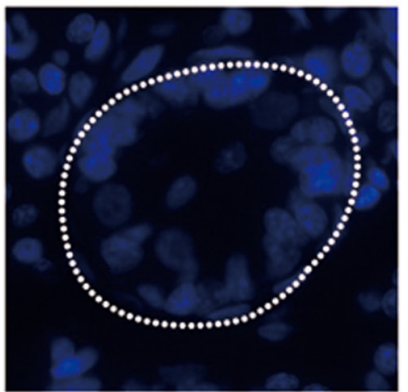

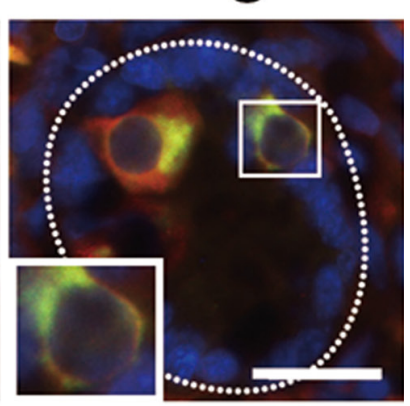

merge

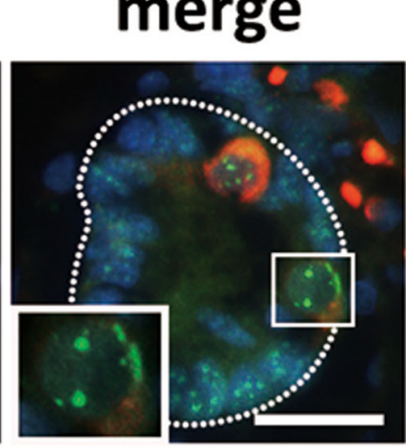

merge

merge

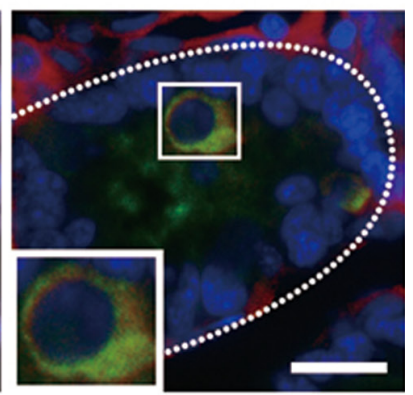

merge

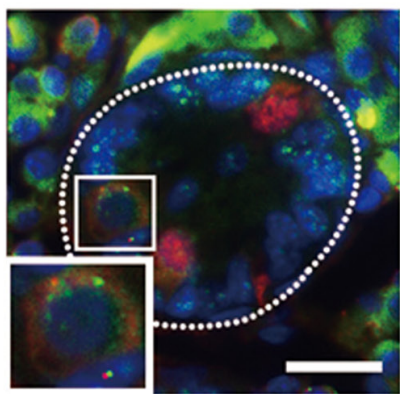

Figure 3 Cellular distribution of SETDB1 and H3K9me3 in the seminiferous tubules during porcine testis development. (A) Co-immunofluorescence detection of glial cell-derived neurotrophic factor receptor alpha-1 (GFRA1) (a marker for gonocytes/undifferentiated spermatogonia) and SETDB1 or H3K9me3 in the neonatal piglet testes. (B) Co-immunofluorescence detection of GFRA1 and SETDB1 or $\mathrm{H} 3 \mathrm{~K} 9 \mathrm{me} 3$ in the 2-month-old pig testes. White boxes were shown at higher magnification. Bars $=20 \mu \mathrm{m}$. 

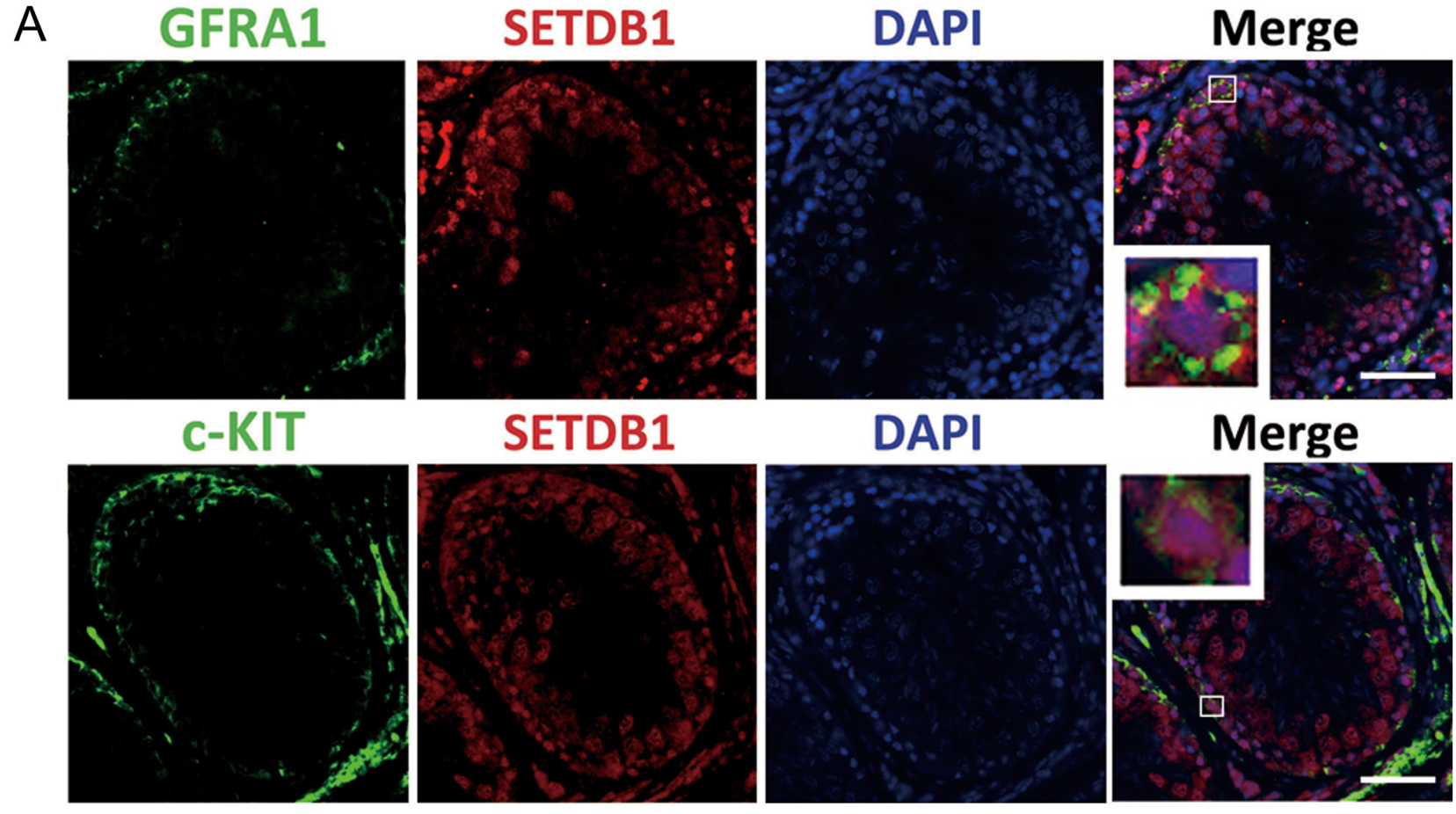

SETDB1

DAPI

Merge
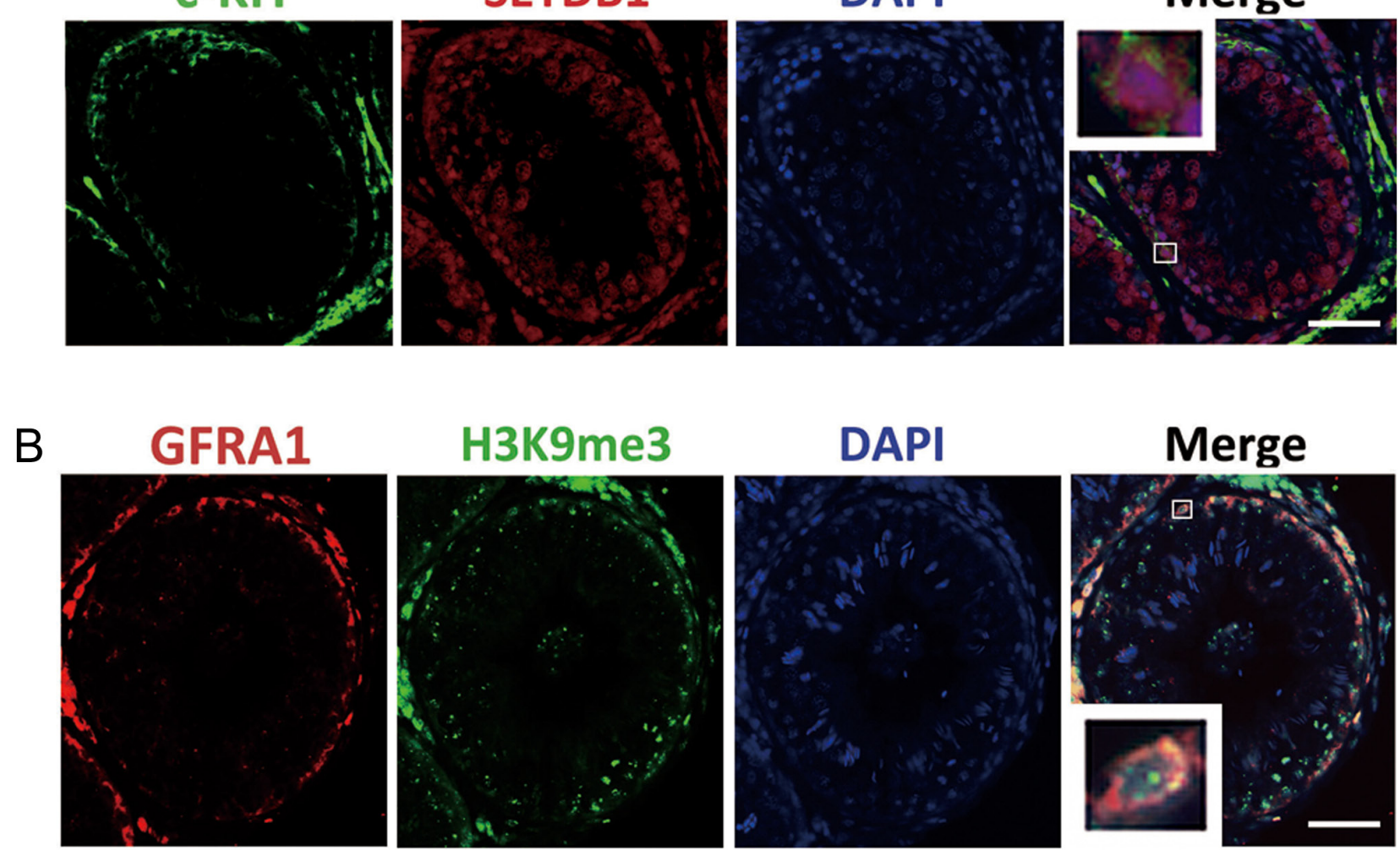

H3K9me3

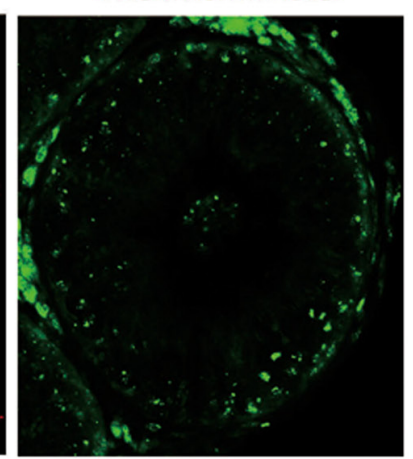

DAPI

Merge
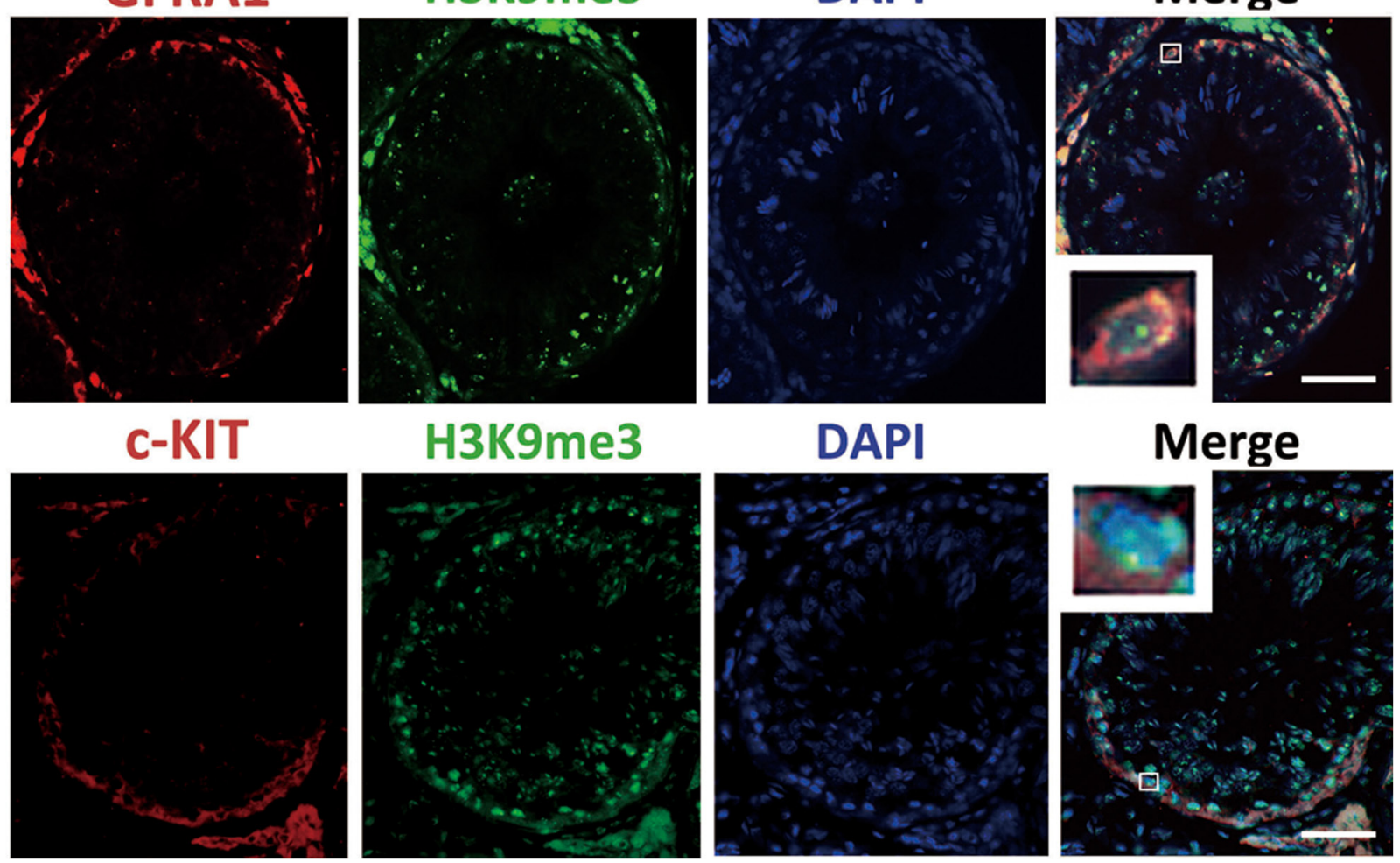

Figure 4 Cellular distribution of SETDB1 and H3K9me3 in porcine adult testis tissue. (A) Co-immunofluorescence staining of SETDB1 and GFRA1 (a marker for undifferentiated spermatogonia) or c-KIT (a marker for differentiated spermatogonia). GFRA1: green; c-KIT: green; SETDB1: red; DAPI: blue (counterstaining of DNA). (B) Co-immunofluorescence staining of H3K9me3 and GFRA1 or C-KIT. GFRA1: red; C-KIT: red; H3K9me3: green; DAPI: blue (counterstaining of DNA). White boxes were shown at higher magnification. Bars $=50 \mu \mathrm{m}$. 
A

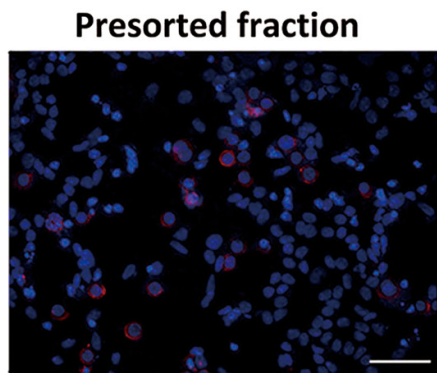

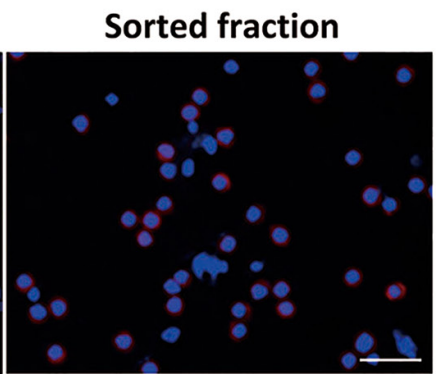

B

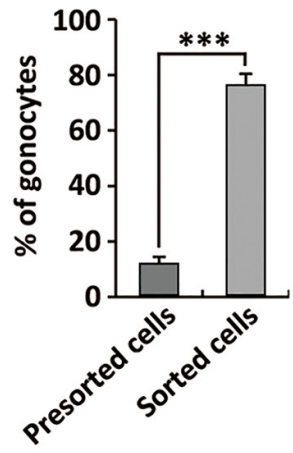

C

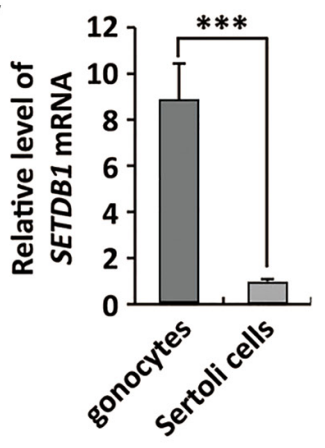

D

$\mathrm{E}$
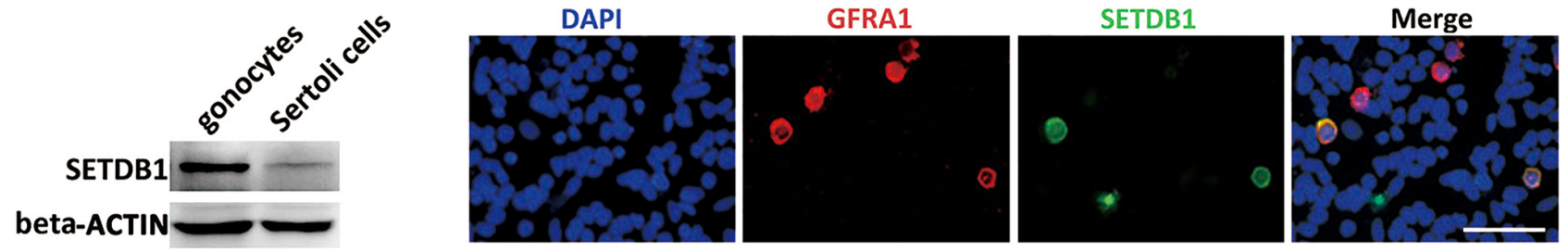

Figure 5 Enrichment of gonocytes and expression of SETDB1 in gonocytes and Sertoli cells. (A) Enrichment of gonocytes by different plating. Immunofluorescence of GFRA1 (red) and DAPI (blue) were performed to calculate the number of gonocytes. Bars $=50 \mu \mathrm{m}$. (B) Proportion of gonocytes (GFRA1-positive cells) before and after enrichment. After enrichment, the purity of gonocytes was $76.5 \% \pm 3.9 \%$ while it was $12.3 \% \pm 2.2 \%$ before the enrichment. ${ }^{* * *} P<0.001$. (C) qPCR analysis of SETDB1 mRNA level in gonocytes or Sertoli cells. The transcriptional level of SETDB1 in gonocytes is 8.9-fold that of Sertoli cells. ${ }^{* *} P<0.001$. (D) Western blot detection of SETDB1 expression in gonocytes and Sertoli cells. (E) Co-immunofluorescent staining of GFRA1 and SETDB1 in the cells before enrichment of gonocytes. SETDB1 mainly expressed in gonocytes (GFRA1-positive cells). GFRA1: red; SETDB1: green; DAPI: blue (counterstaining of DNA). Bars $=50 \mu \mathrm{m}$.

A

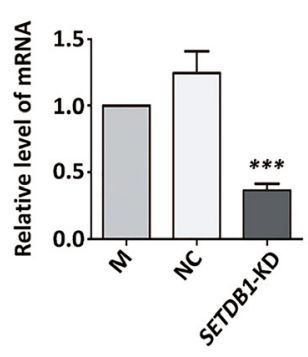

B

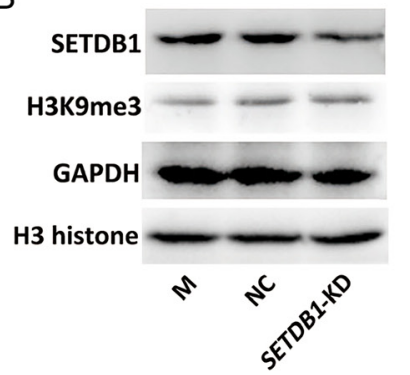

C

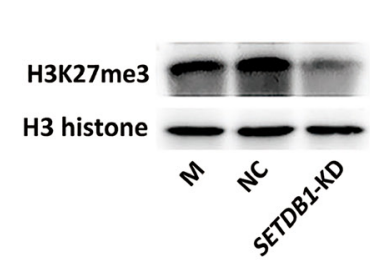

D

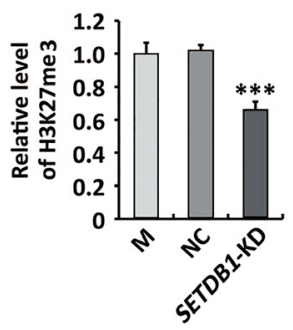

E

E
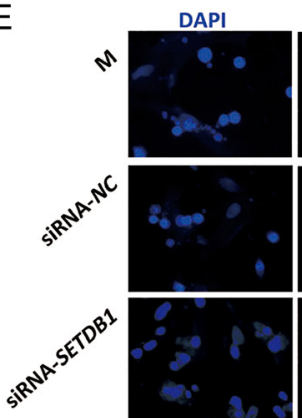
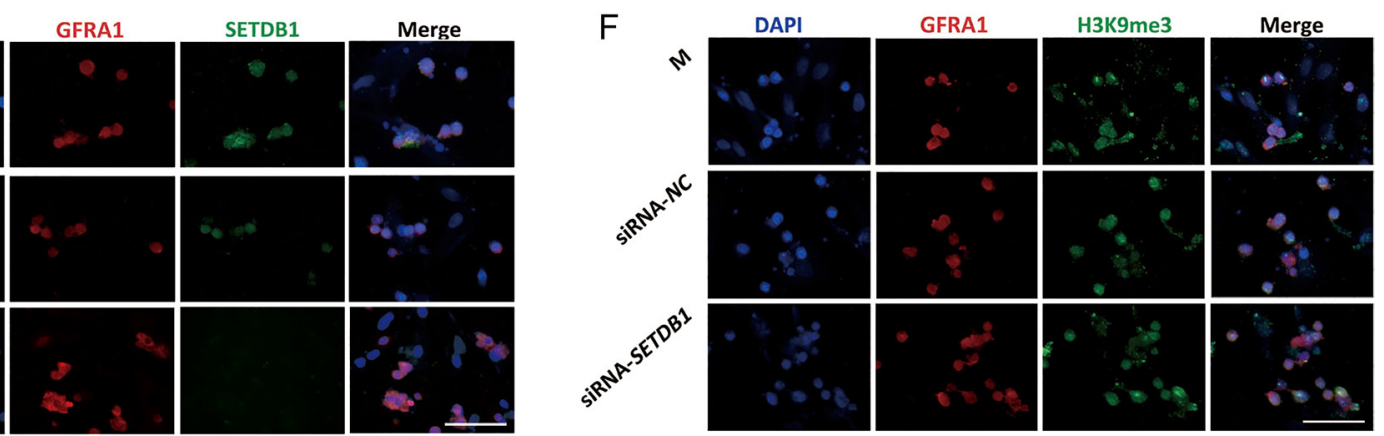

Figure 6 Knockdown of SETDB1 decreased protein expression. (A) qRT-PCR detected the expression of SETDB1 in SETDB1-KD, NC and Mock group. ${ }^{* * *} P<0.001$. (B) Western blot detected SETDB1 expression in treated group. (C) H3K27me3 level was detected by Western blot. (D) $\mathrm{H} 3 \mathrm{~K} 27 \mathrm{me} 3$ intensity analysis was calculated by Image.. ${ }^{* * *} P<0.001$. (E and F) Immunofluorescent staining of SETDB1 and H3K9me3 in SETDB1-KD gonocytes. GFRA1: red; SETDB1: green; H3K9me3: green; DAPI: blue (counterstaining of DNA). Bars $=50 \mu \mathrm{m}$. 
A
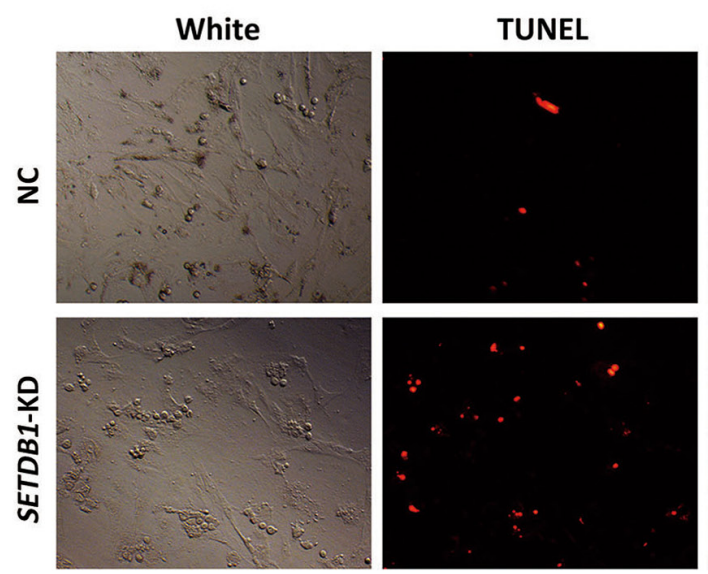

C

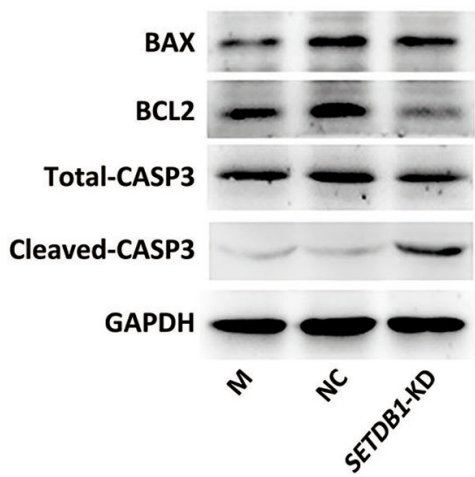

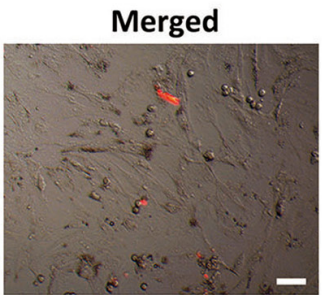

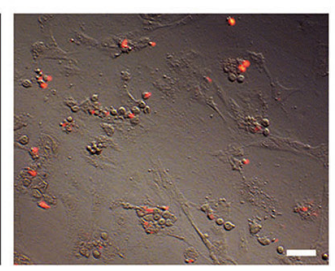

B

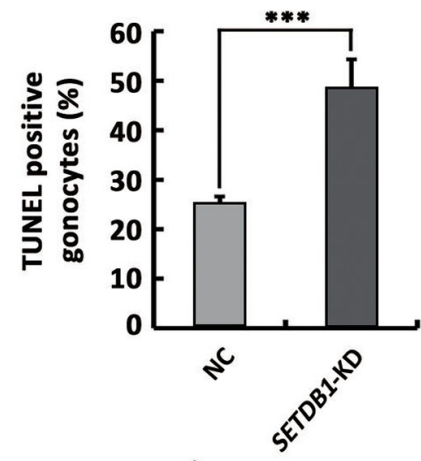

$E$
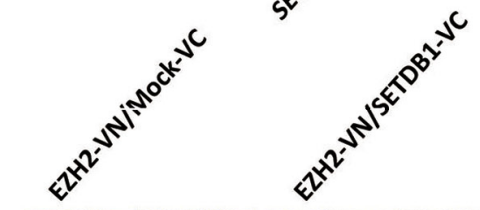

IB:SETDB1
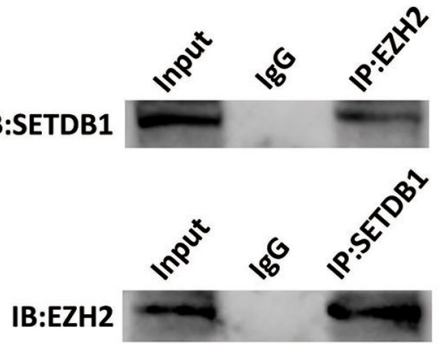
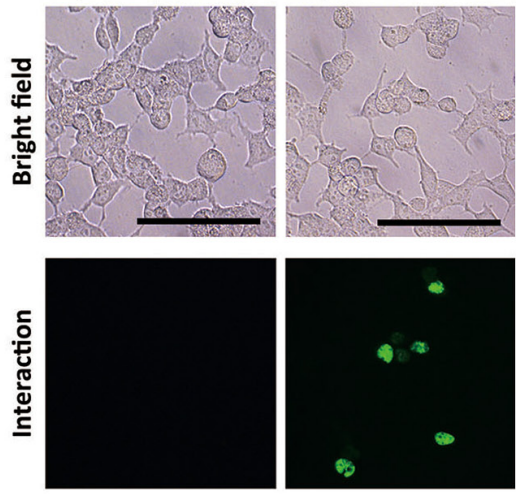

Figure 7 Knockdown of SETDB1 induced gonocyte apoptosis. (A) TUNEL-positive cells apparently increased in SETDB1-deficient gonocytes compared to the control. Red: TUNEL positive cells. Bars $=50 \mu \mathrm{m}$. (B) The statistical analysis of TUNEL-positive gonocytes in treated group. ${ }^{* * *} P<0.001$. (C) Western blot detected apoptosis-related proteins. (D) Co-IP assay was performed to detect the interaction of SETDB1 and EZH2 by Western blot using anti-SETDB1 and anti-EZH2 primary antibodies. (E) BiFC assay. Plasmids expressing SETDB1-VC and EZH2-VN were co-transfected into HEK 293T cells. The fluorescence was detected at $48 \mathrm{~h}$ post-transfection. Bars $=50 \mu \mathrm{m}$.

stem/progenitor cells in mice (An et al. 2014). Here, for the first time, we demonstrate that SETDB1 plays an essential role in maintenance survival of porcine gonocytes, which are the progenitor cells of spermatogonial stem cells.

In the present study, we revealed that SETDB1 was strongly expressed in gonocytes, which suggests that SETDB 1 may have a specific role for maintenance of the gonocyte pool. SETDB1 was expressed in both cytoplasm and nuclei, in porcine gonocytes, which is consistent with the previous reports in HeLa and NIH3T3 cells (Loyola et al. 2006, Cho et al. 2013). Previous reports suggested that human and mouse SETDB1 have nuclear export signals (NESs) and nuclear localization signals (NLSs), making the nucleocytoplasmic shift (Cho et al. 2013, Kang 2015, Tachibana et al. 2015). We speculate that porcine SETDB1 may contain these motifs. In addition, by using proteasome inhibitor and nuclear export inhibitor leptomycin B, Tachibana et al. (2015) found that the intranuclear SETDB1 undergoes protease degradation and exports from the nuclei to the cytoplasm (Tachibana et al. 2015). Thus, SETDB1 is extensively distributed in cytoplasm. Moreover, SETDB1, as a H3K9 monomethyltransferase on free/nonnucleosomal $\mathrm{H} 3$, also mediates $\mathrm{H} 3 \mathrm{~K} 9 \mathrm{me} 1$ in cytoplasm (Towbin et al. 2012, Mozzetta et al. 2015). Furthermore, we detected the distribution of $\mathrm{H} 3 \mathrm{~K} 9 \mathrm{me} 3$ in porcine germ cells, and found that $\mathrm{H} 3 \mathrm{~K} 9 \mathrm{me} 3$ was distributed in the perinuclear region of gonocytes and undifferentiated spermatogonia, which is in line with the previous studies in mice (Payne \& Braun 2006, An et al. 2014). Previous studies revealed that $\mathrm{H} 3 \mathrm{~K} 9 \mathrm{me} 3$ staining patterns shift from a perinuclear to a punctate distribution during SSC differentiation (Payne \& Braun 2006). This perinuclear distribution can be a novel marker for male germline stem cells (Payne \& Braun 2006), and ensures a robust spatial separation of active and inactive chromatin domains (Towbin et al. 2012).

Knockdown of SETDB1 induced gonocyte apoptosis. However, unexpectedly, interference SETDB1 in porcine gonocytes led to no change in $\mathrm{H} 3 \mathrm{~K} 9 \mathrm{me} 3$ level, which is in agreement with the previous report in ES 
cells (Dodge et al. 2004). These findings suggest that other histone methyltransferases are also involved in catalyzing H3K9 trimethylation. In addition to SETDB1, protein G9A (also known as EHMT2), G9A-like protein 1 (GLP; also known as EHMT1) and SUV39H1 (also known as KMT1A) also catalyze methylation at H3K9. G9a and GLP can catalyze H3K9 from zero to mono-, di- and trimethylation in vitro (Collins et al. 2005, Kubicek et al. 2007). In euchromatic regions, G9a and GLP are mainly involved in $\mathrm{H} 3 \mathrm{~K} 9 \mathrm{me} 1$ and $\mathrm{H} 3 \mathrm{~K} 9 \mathrm{me} 2$ (Tachibana et al. 2005). The H3K9me3 levels are maintained by SUV39H1 and/or SETDB1 (Peters et al. 2003, Rice et al. 2003). SUV39H1 can also methylate unmethylated H3K9 (Rea et al. 2000), but more likely to catalyze H3K9me1 to H3K9me2 and H3K9me3 marks (Loyola et al. 2006). Therefore, knockdown of SETDB1 does not absolutely result in a reduction of $\mathrm{H} 3 \mathrm{~K} 9 \mathrm{me} 3$.

The previous studies have shown that the reciprocal action between SETDB1 and Polycomb Repressive Complex 2 (PRC2) regulate ES cell pluripotency and differentiation (Fei et al. 2015). Knockdown of SETDB1 reduces the combination of $E Z H 2$ (a component of PRC2) as well as the level of H3K27me3 in mouse ES cells (Fei et al. 2015). Moreover, Liu et al. (2014) reported that SETDB1 played an essential role in establishing and/or maintaining $\mathrm{H} 3 \mathrm{~K} 27 \mathrm{me} 3$ and H3K9me3 at some retrotransposition loci in the prenatal germline (Liu et al. 2014). In addition, increasing evidence demonstrated that $\mathrm{EZH} 2$ regulated cell proliferation and apoptosis via depositing H3K27me3 (Girard et al. 2014, Zhang et al. 2014, He et al. 2015, Ren et al. 2015). Thus, we detected the global H3K27me3 level and found that knockdown of SETDB1 induced the decrease of H3K27me3 level in porcine gonocytes, which is consistent with that in murine primordial germ cells (Liu et al. 2014) and neurons (Fei et al. 2015).

Furthermore, bimolecular fluorescence complementation (BiFC) has been used to study the protein interactions in cells (Hu et al. 2002). The Co-IP and BiFC assay indicated that porcine SETDB1 indeed interacted with porcine EZH2. Knockdown of SETDB1 resulted in apoptosis and the decrease of H3K27me3 level in porcine gonocytes, which is consistent with that in murine primordial germ cells (Liu et al. 2014) and neurons (Fei et al. 2015), but did not affect the expression of EZH2 (Supplementary Fig. 5). Thus, SETDB1-KD induced gonocyte apoptosis via interacting with $\mathrm{EZH} 2$ to regulate $\mathrm{H} 3 \mathrm{~K} 27 \mathrm{me} 3$ level. Further investigation is needed to elucidate the mechanisms by which SETDB1 regulates $\mathrm{H} 3 \mathrm{~K} 27 \mathrm{me} 3$ and apoptosis in porcine gonocytes.

Finally, the seminiferous tubules of 1-week-old boar testis tissue are mainly composed of Sertoli cells and gonocytes. Depletion of SETDB1 induced apoptosis of gonocytes, but did not lead to apoptosis in Sertoli cells. Therefore, although the purity of gonocytes was
$76.5 \%$, the contaminated Sertoli cells probably did not affect the observations obtained in the present study. To rule out the possible effect from the Sertoli cells, future study is needed to enrich the gonocytes through magnetic-activated cell sorting or fluorescence-activated cell sorting.

In conclusion, knockdown of SETDB1 induced gonocyte apoptosis. SETDB1 plays an important role in maintaining the gonocyte pool, probably due to the regulation of $\mathrm{H} 3 \mathrm{~K} 27 \mathrm{me} 3$ rather than $\mathrm{H} 3 \mathrm{~K} 9 \mathrm{me} 3$. We speculate that SETDB1 may maintain the stem cell characteristics and survival of gonocytes/SSCs through repressing the transcription of differentiation related and pro-apoptotic genes. The findings from this study may provide some insight on the establishment of a successful culture system for porcine germline stem cells.

\section{Supplementary data}

This is linked to the online version of the paper at http://dx.doi. org/10.1530/REP-17-0107.

\section{Declaration of interest}

The authors declare that there is no conflict of interest that could be perceived as prejudicing the impartiality of the research reported.

\section{Funding}

This study was supported in part by National Basic Research Program of China (973 program; 2014CB943100), the National Natural Science Foundation of China (Grant No. 31272439, 31230048) and the Doctoral Program Foundation of Higher Education of China (Grant No. 20130204110017) to W Z.

\section{Acknowledgements}

The authors thank $\mathrm{Dr}$ Xiaodong $\mathrm{Xu}$ for kindly providing pBiFC-VN173 and pBiFC-VC155 plasmids, and Drs Wuzi Dong and Chuanying Pan for suggestions and comments. We thank Dr Huayan Wang for proofreading the manuscript.

\section{References}

An J, Zhang X, Qin J, Wan Y, Hu Y, Liu T, Li J, Dong W, Du E, Pan C et al. 2014 The histone methyltransferase ESET is required for the survival of spermatogonial stem/progenitor cells in mice. Cell Death and Disease $\mathbf{5}$ e1196. (doi:10.1038/cddis.2014.171)

Bilodeau S, Kagey MH, Frampton GM, Rahl PB \& Young RA 2009 SetDB1 contributes to repression of genes encoding developmental regulators and maintenance of ES cell state. Genes and Development 23 2484-2489. (doi:10.1101/gad.1837309)

Cho S, Park JS \& Kang YK 2013 Regulated nuclear entry of over-expressed Setdb1. Genes to Cells 18 694-703. (doi:10.1111/gtc.12068)

Collins RE, Tachibana M, Tamaru H, Smith KM, Jia D, Zhang X, Selker EU, Shinkai Y \& Cheng X 2005 In vitro and in vivo analyses of a Phe/Tyr switch 
controlling product specificity of histone lysine methyltransferases. Journal of Biological Chemistry 280 5563-5570. (doi:10.1074/jbc. M410483200)

Culty M 2009 Gonocytes, the forgotten cells of the germ cell lineage. Birth Defects Research Part C: Embryo Today 87 1-26. (doi:10.1002) bdrc.20142)

Dodge JE, Kang YK, Beppu H, Lei H \& Li E 2004 Histone H3-K9 methyltransferase ESET is essential for early development. Molecular and Cellular Biology 24 2478-2486. (doi:10.1128/MCB.24.6.24782486.2004)

Du TT \& Huang QH 2007 The roles of histone lysine methylation in epigenetic regulation. Yi Chuan: Hereditas/Zhongguo Yi Chuan Xue Hui Bian Ji 29 387-392. (doi:10.1360/yc-007-0387)

Eddy EM 2002 Male germ cell gene expression. Recent Progress in Hormone Research 57 103-128. (doi:10.1210/rp.57.1.103)

Fei Q, Yang X, Jiang H, Wang Q, Yu Y, Yu Y, Yi W, Zhou S, Chen T, Lu C et al. 2015 SETDB1 modulates PRC2 activity at developmental genes independently of $\mathrm{H} 3 \mathrm{~K} 9$ trimethylation in mouse ES cells. Genome Research 25 1325-1335. (doi:10.1101/gr.177576.114)

Franca LR, Hess RA, Dufour JM, Hofmann MC \& Griswold MD 2016 The Sertoli cell: one hundred fifty years of beauty and plasticity. Andrology 4 189-212. (doi:10.1111/andr.12165)

Frojdman K, Harley VR \& Pelliniemi LJ 2000 Sox9 protein in rat sertoli cells is age and stage dependent. Histochemistry and Cell Biology 113 31-36. (doi:10.1007/s004180050004)

Gaskell TL, Esnal A, Robinson LL, Anderson RA \& Saunders PT 2004 Immunohistochemical profiling of germ cells within the human fetal testis: identification of three subpopulations. Biology of Reproduction 71 2012-2021. (doi:10.1095/biolreprod.104.028381)

Girard N, Bazille C, Lhuissier E, Benateau H, Llombart-Bosch A, Boumediene K \& Bauge C 2014 3-Deazaneplanocin A (DZNep), an inhibitor of the histone methyltransferase EZH2, induces apoptosis and reduces cell migration in chondrosarcoma cells. PLOS ONE 9 e98176. (doi:10.1371/journal.pone.0098176)

Goel S, Fujihara M, Minami N, Yamada M \& Imai H 2008 Expression of NANOG, but not POU5F1, points to the stem cell potential of primitive germ cells in neonatal pig testis. Reproduction 135 785-795. (doi:10.1530/REP-07-0476)

He SB, Zhou H, Zhou J, Zhou GQ, Han T, Wan DW, Gu W, Gao L, Zhang Y, Xue XF et al. 2015 Inhibition of EZH2 expression is associated with the proliferation, apoptosis, and migration of SW620 colorectal cancer cells in vitro. Experimental Biology and Medicine 240 458-466. (doi:10.1177/1535370214542215)

Hu CD, Chinenov Y \& Kerppola TK 2002 Visualization of interactions among bZIP and Rel family proteins in living cells using bimolecular fluorescence complementation. Molecular Cell 9 789-798. (doi:10.1016/s1097-2765(02)00496-3)

Kang YK 2015 SETDB1 in early embryos and embryonic stem cells. Current Issues in Molecular Biology 17 1-10. (doi:10.21775/cimb.017.001)

Kouzarides T 2002 Histone methylation in transcriptional control. Current Opinion in Genetics and Development 12 198-209. (doi:10.1016/ S0959-437X(02)00287-3)

Kubicek S, O'Sullivan RJ, August EM, Hickey ER, Zhan Q, Teodoro ML, Rea S, Mechtler K, Kowalski JA, Homon CA et al. 2007 Reversal of H3K9me2 by a small-molecule inhibitor for the G9a histone methyltransferase. Molecular Cell 25 473-481. (doi:10.1016/j.molcel.2007.01.017)

Lawson KA, Teteak CJ, Gao J, Li N, Hacquebord J, Ghatan A, ZielinskaKwiatkowska A, Song G, Chansky HA \& Yang L 2013 ESET histone methyltransferase regulates osteoblastic differentiation of mesenchymal stem cells during postnatal bone development. FEBS Letters $\mathbf{5 8 7}$ 3961-3967. (doi:10.1016/j.febslet.2013.10.028)

Lee KH, Lee WY, Kim JH, Yoon MJ, Kim NH, Kim JH, Uhm SJ, Kim DH, Chung HJ \& Song H 2013 Characterization of GFRalpha-1-positive and GFRalpha-1-negative spermatogonia in neonatal pig testis. Reproduction in Domestic Animals 48 954-960. (doi:10.1111/rda.12193)

Liu S, Brind'Amour J, Karimi MM, Shirane K, Bogutz A, Lefebvre L, Sasaki H, Shinkai Y \& Lorincz MC 2014 Setdb1 is required for germline development and silencing of $\mathrm{H} 3 \mathrm{~K} 9 \mathrm{me} 3$-marked endogenous retroviruses in primordial germ cells. Genes and Development 28 2041-2055. (doi:10.1101/gad.244848.114)
Lohmann F, Loureiro J, Su H, Fang Q, Lei H, Lewis T, Yang Y, Labow M, Li E, Chen T et al. 2010 KMT1E mediated H3K9 methylation is required for the maintenance of embryonic stem cells by repressing trophectoderm differentiation. Stem Cells 28 201-212.

Loyola A, Bonaldi T, Roche D, Imhof A \& Almouzni G 2006 PTMs on H3 variants before chromatin assembly potentiate their final epigenetic state. Molecular Cell 24 309-316. (doi:10.1016/j.molcel.2006.08.019)

Manku G \& Culty M 2015 Mammalian gonocyte and spermatogonia differentiation: recent advances and remaining challenges. Reproduction 149 R139-R157. (doi:10.1530/REP-14-0431)

Martin C \& Zhang Y 2005 The diverse functions of histone lysine methylation. Nature Reviews: Molecular Cell Biology 6 838-849. (doi:10.1038/nrm1761)

Mozzetta C, Boyarchuk E, Pontis J \& Ait-Si-Ali S 2015 Sound of silence: the properties and functions of repressive Lys methyltransferases. Nature Reviews: Molecular Cell Biology 16 499-513. (doi:10.1038/ nrm4029)

Payne C \& Braun RE 2006 Histone lysine trimethylation exhibits a distinct perinuclear distribution in Plzf-expressing spermatogonia. Developmental Biology 293 461-472. (doi:10.1016/j.ydbio.2006.02.013)

Peters AH, Kubicek S, Mechtler K, O'Sullivan RJ, Derijck AA, PerezBurgos L, Kohlmaier A, Opravil S, Tachibana M, Shinkai Y et al. 2003 Partitioning and plasticity of repressive histone methylation states in mammalian chromatin. Molecular Cell 12 1577-1589. (doi:10.1016/ S1097-2765(03)00477-5)

Rea S, Eisenhaber F, O'Carroll N, Strahl BD, Sun ZW, Schmid M, Opravil S, Mechtler K, Ponting CP, Allis CD et al. 2000 Regulation of chromatin structure by site-specific histone H3 methyltransferases. Nature $\mathbf{4 0 6}$ 593-599. (doi:10.1038/35020506)

Ren XQ, Bai X, Zhang XF, Li ZY, Tang LF, Zhao XY, Li ZY, Ren YF, Wei SC, Wang QS et al. 2015 Quantitative nuclear proteomics identifies that miR-137-mediated $\mathrm{EZH} 2$ reduction regulates resveratrol-induced apoptosis of neuroblastoma cells. Molecular and Cellular Proteomics 14 316-328. (doi:10.1074/mcp.M114.041905)

Rice JC, Briggs SD, Ueberheide B, Barber CM, Shabanowitz J, Hunt DF, Shinkai Y \& Allis CD 2003 Histone methyltransferases direct different degrees of methylation to define distinct chromatin domains. Molecular Cell 12 1591-1598. (doi:10.1016/S1097-2765(03)00479-9)

Schultz DC, Ayyanathan K, Negorev D, Maul GG \& Rauscher FJ 2002 SETDB1: a novel KAP-1-associated histone H3, lysine 9-specific methyltransferase that contributes to HP1-mediated silencing of euchromatic genes by KRAB zinc-finger proteins. Genes and Development 16 919-932. (doi:10.1101/gad.973302)

Spencer VA \& Davie JR 1999 Role of covalent modifications of histones in regulating gene expression. Gene 240 1-12. (doi:10.1016/S03781119(99)00405-9)

Swindle MM, Makin A, Herron AJ, Clubb FJ Jr \& Frazier KS 2012 Swine as models in biomedical research and toxicology testing. Veterinary Pathology 49 344-356. (doi:10.1177/0300985811402846)

Tachibana M, Ueda J, Fukuda M, Takeda N, Ohta T, Iwanari H, Sakihama T, Kodama T, Hamakubo T \& Shinkai Y 2005 Histone methyltransferases G9a and GLP form heteromeric complexes and are both crucial for methylation of euchromatin at H3-K9. Genes and Development 19 815-826. (doi:10.1101/gad.1284005)

Tachibana K, Gotoh E, Kawamata N, Ishimoto K, Uchihara Y, Iwanari H, Sugiyama A, Kawamura T, Mochizuki Y, Tanaka T et al. 2015 Analysis of the subcellular localization of the human histone methyltransferase SETDB1. Biochemical and Biophysical Research Communications 465 725-731. (doi:10.1016/j.bbrc.2015.08.065)

Tan SL, Nishi M, Ohtsuka T, Matsui T, Takemoto K, Kamio-Miura A, Aburatani H, Shinkai Y \& Kageyama R 2012 Essential roles of the histone methyltransferase ESET in the epigenetic control of neural progenitor cells during development. Development 139 3806-3816. (doi:10.1242/ dev.082198)

Towbin BD, Gonzalez-Aguilera C, Sack R, Gaidatzis D, Kalck V, Meister P, Askjaer P \& Gasser SM 2012 Step-wise methylation of histone H3K9 positions heterochromatin at the nuclear periphery. Cell 150 934-947. (doi:10.1016/j.cell.2012.06.051)

Yang L, Xia L, Wu DY, Wang H, Chansky HA, Schubach WH, Hickstein DD \& Zhang Y 2002 Molecular cloning of ESET, a novel histone H3-specific 
methyltransferase that interacts with ERG transcription factor. Oncogene 21 148-152. (doi:10.1038/sj.onc.1204998)

Yeap LS, Hayashi K \& Surani MA 2009 ERG-associated protein with SET domain (ESET)-Oct4 interaction regulates pluripotency and represses the trophectoderm lineage. Epigenetics and Chromatin 212. (doi:10.1186/1756-8935-2-12)

Yuan P, Han J, Guo G, Orlov YL, Huss M, Loh YH, Yaw LP, Robson P, Lim B \& Ng HH 2009 Eset partners with Oct4 to restrict extraembryonic trophoblast lineage potential in embryonic stem cells. Genes and Development 23 2507-2520. (doi:10.1101/ gad.1831909)
Zhang Q, Padi SK, Tindall DJ \& Guo B 2014 Polycomb protein EZH2 suppresses apoptosis by silencing the proapoptotic miR-31. Cell Death and Disease 5 e1486. (doi:10.1038/cddis.2014.454)

Received 20 February 2017

First decision 16 March 2017

Revised manuscript received 27 March 2017

Accepted 18 April 2017 